\title{
Elevated N-myristoyltransferase activity and expression in oral squamous cell carcinoma
}

\author{
ANURAAG SHRIVASTAV ${ }^{1,3^{*}}$, ANIL R. SHARMA ${ }^{1,3^{*}}$, GAGAN BAJAJ $^{1,3}$, \\ CHANDRASHEKHAR CHARAVARYAMATH ${ }^{4}$, WENDELIN EZZAT ${ }^{1,5}$, PETER SPAFFORD $^{5}$, \\ RICK GORE-HICKMAN ${ }^{5}$, BALJIT SINGH $^{4}$, MARIA A. COPETE ${ }^{2}$ and RAJENDRA K. SHARMA ${ }^{1,3}$ \\ ${ }^{1}$ Department of Pathology and Laboratory Medicine, College of Medicine; ${ }^{2}$ College of Dentistry, University \\ of Saskatchewan, Saskatoon S7N 5E5; ${ }^{3}$ Saskatchewan Cancer Agency, Saskatoon S7N 4H4; \\ ${ }^{4}$ Immunology Research Group, Department of Veterinary Biomedical Sciences and \\ Saskatoon Cancer Center, University of Saskatchewan, Saskatoon \\ S7N 4B4; ${ }^{5}$ St. Paul Hospital, Saskatoon S7M 0Z9, Canada
}

Received December 20, 2006; Accepted February 22, 2007

\begin{abstract}
N-myristoyltransferase (NMT) catalyzes the myristoylation of proteins involved in signal transduction, cellular transformation, differentiation, proliferation and oncogenesis. In this study, we report for the first time on the elevated NMT activity in oral squamous cell carcinoma (OSCC). Increased activity is marked with increased staining for NMT in the OSCC samples compared to the normal adjacent tissues. In addition, we observed increased staining for the N-myristoyltransferase inhibitor protein 71 (NIP71) in the OSCC samples compared to the control tissues. These findings suggest the regulatory relationship between NMT and NIP71 during tumorigenesis. It is possible that the increased activity results in the overexpression of NIP71 in an effort to control NMT activity.
\end{abstract}

\section{Introduction}

Oral squamous cell carcinoma (OSCC) is diagnosed in an estimated 30,000 Americans per year causing more than 8,000 deaths. The disease kills approximately one person every hour of each day. OSCC is currently the sixth most common cancer in men and the fourteenth most common in women. Currently, OSCC remains the most frequent malignant neoplasm of the head and neck region, and health agencies anticipate that only half of those diagnosed will survive more than five years. However, in spite of the high mortality rates

Correspondence to: Dr Rajendra K. Sharma, 20 Campus Drive, Saskatoon Cancer Centre, Saskatoon S7N 4H4, Canada

E-mail: rsharma@scf.sk.ca

${ }^{*}$ Contributed equally

Key words: N-myristoyltransferase, N-myristoyltransferase inhibitor protein/hsc70, oral squamous cell carcinoma it remains one of the most preventable of all cancers. If the disease is discovered in the early stages, cure rates can reach up to $80-90 \%$. The major obstacle is that the majority of patients present in the latter stage of the disease, making it difficult to treat, and this accounts for the high mortality rate (http://www.nidcr.nih.gov/HealthInformation/DiseasesAndC onditions/OralCancer/OralCancer.htm).

OSCC is the most frequent malignant neoplasm of the head and neck region. The conversion of normal cells to cancer cells is achieved through a multi-step process that is closely associated with the accumulation of multiple gene changes including both oncogenes and tumor suppressor genes.

$\mathrm{N}$-myristoylation is an important co-translational lipidic modification of proteins involved in various cellular processes including signaling, cellular transformations and most notably, oncogenesis (1). Myristoylation is the process involving the covalent attachment of myristate, a 14 carbon saturated fatty acid, to the N-terminal glycine residue of a protein $(1,2)$. Myristoylation ensures the proper functioning and intracellular trafficking of proteins. c-Src is the cellular homologue of $\mathrm{v}$-Src, the transforming gene of the Rous sarcoma virus (3) and is the first reported oncoprotein. The myristoylation of cSrc is essential for its membrane attachment and activation (4). The overexpression and/or activation of c-Src is linked genetically and biochemically to the development of several human cancers especially those of the colon and breast $(5,6)$.

The myristoylation of proteins is catalyzed by the enzyme, $\mathrm{N}$-myristoyltransferase (NMT) (7). NMT has been implicated in various diseases and is an emerging therapeutic and drug target (8-13). We have demonstrated, for the first time, the alteration of NMT activity during the progression of cancer $(11,12,14)$. We have also observed a higher NMT activity in the rat model in colonic epithelial neoplasms compared to the corresponding normal colonic tissue. Increases in NMT activity appear at the early stages of colonic carcinogenesis (11). Increased NMT activity has also been observed in human colonic tumors and this was predominantly cytosolic (11). Furthermore, colorectal tumors have shown increased 
immunohistochemical staining for NMT compared to normal mucosae (12). In addition, gallbladder carcinomas have displayed strong cytoplasmic positivity for NMT with an increased intensity in the invasive component, whereas normal gallbladder mucosae have shown weak to negative cytoplasmic staining (14). These findings have significant implications with regard to the prognosis of cancer and the design of chemotherapeutic drugs. Studies from various laboratories including ours have established NMT as a putative therapeutic target for cancer $(9-11,14,15)$.

Schliephake has reviewed some of the molecular markers for OSCC (16). Markers belong to different functionality groups such as the epithelial growth factor (EGF) and the epithelial growth factor receptor (EGF-R, c-erb1-4 or Her2/neu), cyclins (cyclin A, B1, D1, E), the proliferation cell nuclear antigen (PCNA), Ki67/MIB, the argyrophylic nucleolar organiser region-associated proteins (AgNOR), skp2, bcl2/ BAG-1, heat shock proteins (HSP27 and HSP70) and telomerase. Molecular markers alone are not sufficient for the prognosis of OSCC. However, these markers in association with a histopathological evaluation present a better case for the prognosis of OSCC. The increased expression and activity of NMT in colon and gallbladder cancer suggests its involvement in carcinogenesis. We have also demonstrated that the heat shock cognate protein 70 (hsc70), a constitutive active form of hsp70, is homologous to the N-myristoyltransferase inhibitor protein 71 (NIP71). Hsp70 is one of the molecular markers for OSCC, which has led us to study the role of NMT in oral cancer. In this study, we report for the first time on the involvement of NMT in oral cancer.

\section{Materials and methods}

$\left[9,10-{ }^{3} \mathrm{H}\right]$ Myristic acid (39.3 $\left.\mathrm{Ci} / \mathrm{mMol}\right)$ was purchased from Perkin-Elmer (USA). Pseudomonas acyl CoA synthetase was purchased from ICN Biochemicals (USA). The PVDF membrane and powdered milk were purchased from BioRad Laboratories (Canada). The monoclonal antibody to NMT-1 and the HRP-conjugated goat anti mouse antibody were obtained from BD-Biosciences, Canada. Monoclonal antihsc70 was bought from Cedarlane Laboratories (Canada). Chemiluminescence reagent plus was obtained from NEN Life Science products, USA. Peptide substrate based on the $\mathrm{N}$-terminal of pp60 ${ }^{\mathrm{c}-\text { src }}$ (GSSKSKPKR) was synthesized by the Alberta Peptide Institute, Canada. Recombinant human NMT (hNMT) was purified as described previously (17). General laboratory reagents of analytical grade were obtained from Sigma Chemical Co. (Canada).

Preparation of homogenates. Oral cancer tissues and adjacent normal tissues were obtained after written consent was given from the patients and the guidelines of the University of Saskatchewan Ethics Board were followed. Tissue samples were homogenized, using a homogenizing probe twice for $30 \mathrm{sec}$ in $2 \mathrm{ml}$ ice-cold buffer A (PBS containing $0.1 \mathrm{mM}$ EGTA and $10 \mathrm{mM}$ 2-mercaptoethanol) and further centrifuged at $9000 \mathrm{rpm}$ to obtain a clear homogenate.

NMT assay. NMT activity was assayed as described earlier (18). Briefly, $\left[{ }^{3} \mathrm{H}\right]$ myristoyl-CoA was synthesized according to the literature (18). The reaction mixture contained $40 \mathrm{mM}$ Tris-HCl, pH 7.4, $0.1 \mathrm{mM}$ EGTA, $10 \mathrm{mM} \mathrm{MgCl}_{2}, 5 \mathrm{mM}$ ATP, $1 \mathrm{mM}$ LiCoA, $1 \mu \mathrm{M}\left[{ }^{3} \mathrm{H}\right]$ myristic acid $(7.5 \mu \mathrm{Ci})$ and 0.3 units/ $\mathrm{ml}$ Pseudomonas acyl-CoA synthetase in a total volume of $200 \mu \mathrm{l}$. The reaction was carried out for $30 \mathrm{~min}$ at $30^{\circ} \mathrm{C}$. The conversion to $\left[{ }^{3} \mathrm{H}\right]$ myristoyl-CoA was generally $>95 \%$. The assay mixture contained $40 \mathrm{mM}$ Tris- $\mathrm{HCl}, \mathrm{pH} 7.4,0.5 \mathrm{mM}$ EGTA, $0.45 \mathrm{mM}$ 2-mercaptoethanol, 1\% Triton X-100, peptide substrate $(500 \mu \mathrm{M})$ and NMT in a total volume of $25 \mu 1$. The transferase reaction was initiated by the addition of freshly generated $\left[{ }^{3} \mathrm{H}\right]$ myristoyl-CoA and incubated at $30^{\circ} \mathrm{C}$ for $30 \mathrm{~min}$. The reaction was terminated by spotting $15 \mu 1$ aliquots of the incubation mixture onto P81 phosphocellulose paper discs and drying under a stream of warm air. The P81 phosphocellulose paper discs were washed in two changes of $40 \mathrm{mM}$ Tris- $\mathrm{HCl}$, pH 7.3 for $30 \mathrm{~min}$. The radioactivity was quantified in $7.5 \mathrm{ml}$ Beckman Ready Safe Liquid Scintillation mixture in a Beckman Liquid Scintillation Counter. One unit of NMT activity was expressed as 1 pmol myristoyl peptide formed per min.

Immunohistochemical analysis. Both normal and cancerous oral tissues were fixed in $10 \%$ formaldehyde, dehydrated in ascending concentrations of ethanol and xylene, and then embedded in paraffin. Sections (57 $\mu \mathrm{m}$-thick) were prepared and placed on silane-coated slides. The slides were incubated at $55^{\circ} \mathrm{C}$ for $45 \mathrm{~min}$ in an oven in order to enhance the adherence of the sections.

The labeling of the sections with the antibodies was performed as described previously (19). Briefly, the sections were incubated in xylene to remove the paraffin and rehydrated in ethanol followed by the neutralization of endogenous peroxide in $0.5 \% \mathrm{H}_{2} \mathrm{O}_{2}$ in methanol. The sections were treated with pepsin $(2 \mathrm{mg} / \mathrm{ml} 0.01 \mathrm{~N} \mathrm{HCl})$ for $45 \mathrm{~min}$ to expose the antigens and blocked with $1 \%$ BSA in PBS for $30 \mathrm{~min}$. The sections were reacted with anti-human NMT antibody (dilution, 1:100) for 90 min and HRP-conjugated secondary antibodies (dilution, 1:100) for 45 min followed by color development. The controls included the omission of the primary antibody or both the primary and secondary anti-bodies to determine, respectively, the non-specific binding of the secondary antibody and the inhibition of endogenous tissue peroxidase. Another control section was incubated with the anti-von Willebrand Factor antibody (dilution, 1:100) that delineates blood vessels. The stained sections were examined and photographed.

Other methods. Proteins were estimated by the Bradford method (20). GraphPad Prism ${ }^{\circledR}$ software was used for the statistical analysis.

\section{Results and Discussion}

A total of ten samples were analyzed, including five normal and five malignant samples. In addition, the role of NMT activity and protein expression studies were performed in the tissue samples provided. Duplicate tissue sections were then reviewed by a co-investigator to determine the location and boundaries of the H\&E-stained tissue sections. The oral tissue samples consisted of three patients with carcinoma of the tongue and two with right tonsillar carcinoma. 


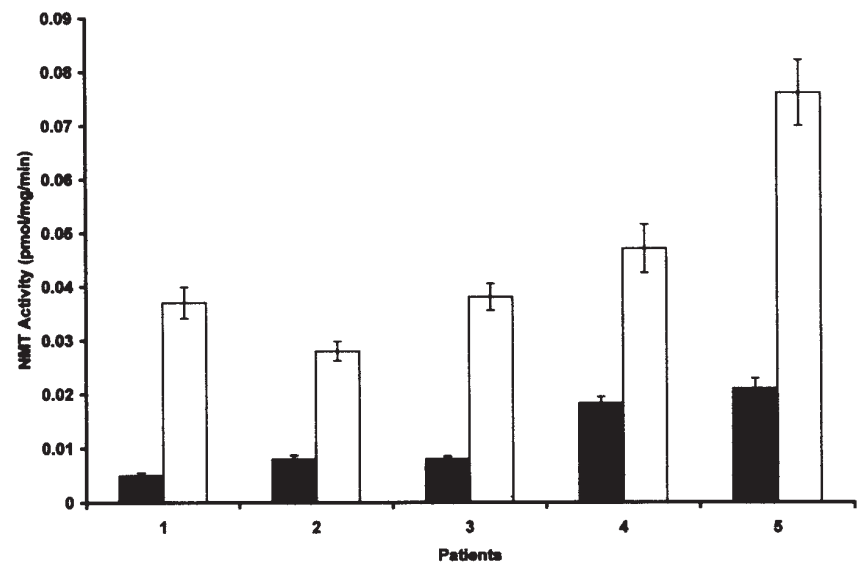

Figure 1. N-myristoyltransferase (NMT) activity in the oral samples. NMT activity was determined in the oral tissue homogenates of oral squamous cell carcinoma (OSCC) patients (1-5) as described in 'Materials and methods' using pp60 $60^{\text {src }}$ as the substrate. $\square$, OSCC sample; $\mathbf{n}$, adjacent normal tissue. Values are means \pm SD of three independent experiments.

NMT activity in the OSCC samples. NMT activity was determined in the tumor region and the normal region from the same patient. In total we analyzed eight paired samples from OSCC patients including a normal and tumor tissue sample. NMT activity was carried out, as described in the 'Materials and methods' section, in the presence of the pp60 $0^{\text {src }}$-derived peptide substrate. We found that NMT activity was $\sim 2.5$ folds higher in the tumor samples as compared to the normal sample of the same patient (Fig. 1). The increased NMT activity could be due to several reasons. One of the reasons could be the increased demand of the myristoylation of various proteins/oncoproteins involved in tumorigenesis. For instance, the levels of the myristoylated tyrosine kinases, pp60 6 -src and pp60 c-yes, are several folds higher in colonic preneoplastic lesions and neoplasms compared with normal colon cells $(21,22)$. It is possible, that the high NMT activity in the neoplasia could result into the aberrant myristoylation of proteins which are otherwise not usually myristoylated. For example, the N-myristoylation of the normal cellular protein, p21 ras, resulted in potent transformation activity (23). The myristoylation of H-ras and K-ras altered the subcellular localization and significantly affected the activation of MAP kinase (24).

Immunohistochemical staining of NMT and its inhibitory protein in OSCC samples. The increased NMT activity observed above could be due to the overexpression of the protein during tumorigenesis or the differential regulation of the NMT activity by other NMT regulator proteins. First, we stained normal and OSCC samples with H\&E in order to depict the cancerous growth in the oral tissues. Normal oral tissues exhibit a normal growth with tight cellular morphology and an unremarkable surface epithelium (Fig. 2, normal), whereas OSSC samples reveal islands of malignant squamous epithelium invading into the lamina propria (Fig. 2, tumor). In order to study the reason for the enhanced NMT activity, we determined the NMT expression and localization by immunohistochemical analysis, which revealed increased staining of NMT in the tumor samples compared to the adjacent normal oral tissue (Fig. 3). Generally, NMT is a cytoplasmic protein and is mostly cytoplasmic in normal epithelial cells (Fig. 3, normal), although nuclear localization is also evident in cancerous epithelial cells (Fig. 3, tumor). We have shown earlier that during ischemia, NMT is rendered nuclear in cardiac cells (25). The altered localization of NMT could be due to stress. It is possible that due to the tumor load, squamous cells are undergoing stress and this results in the altered localization of NMT. These results suggest that the increased NMT activity could be due to the overexpression of total NMT in general.

NMT activity can be regulated by NIP71 (26). We have recently demonstrated that NIP71 is homologous to hsc70 (27). The cell synthesis of heat shock proteins is increased by a variety of environmental and pathophysiological stressful conditions. The 70-kDa heat shock protein family which constitutively expresses hsc70 and heat-inducible hsp70 is thought to be involved in oncogene products. Various studies have implicated both hsc70 and hsp70 in the diagnosis of OSCC and other cancer types $(28,29)$. The differential expression of hsp70 during oral tumorigenesis has also been reported (30). The overexpression of hsp70 in oral cancer is not merely a molecular marker but is also implicated in the pathogenesis of oral cancer (30). We observed positive staining
Normal

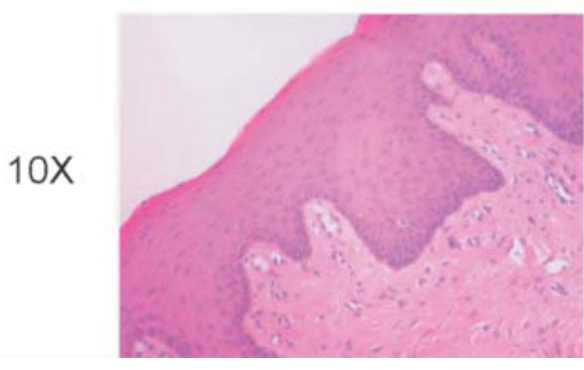

Tumor

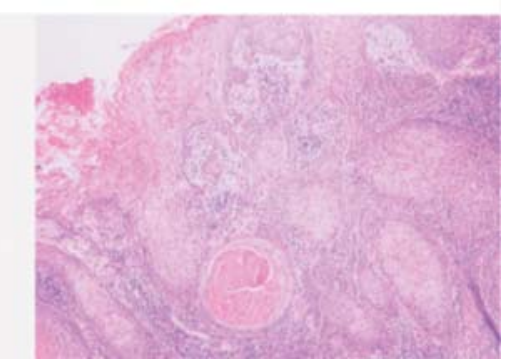

Figure 2. H\&E staining of the normal and oral squamous cell carcinoma (OSCC) sample. The normal sample shows an unremarkable surface epithelium, whereas the OSCC sample shows islands of malignant squamous epithelium invading into the lamina propria at x10 original magnification in the photomicrograph. 
Normal
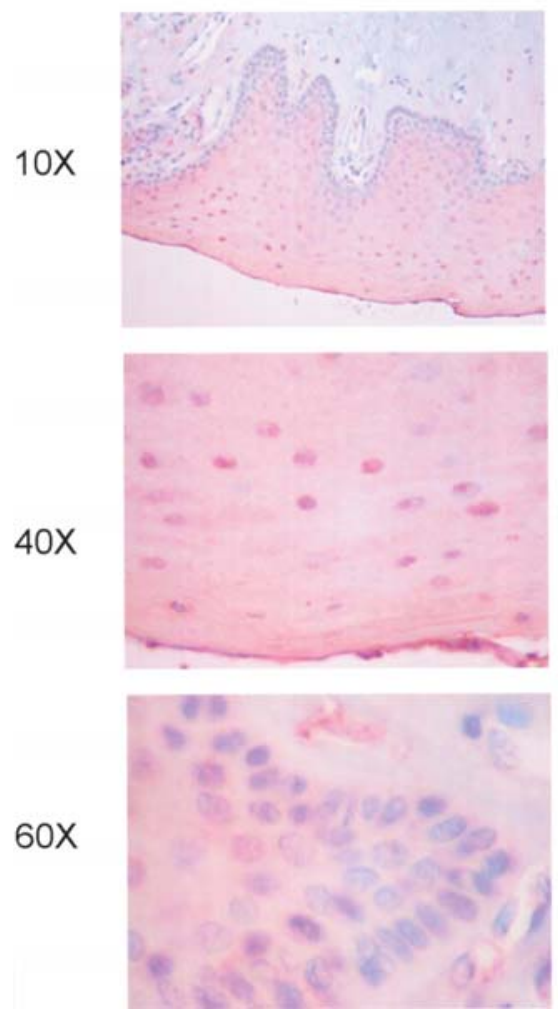

Tumor
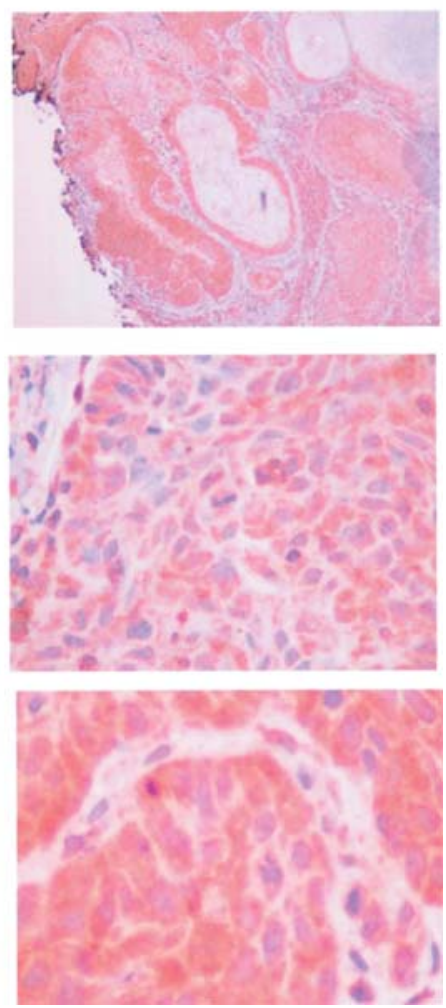

Figure 3. Immunohistochemical analysis of normal and tumor oral samples from patients. The immunohistochemical analysis of normal or tumor oral tissues was carried out as described in 'Materials and methods'. Weak staining of N-myristoyltransferase was observed in the normal adjacent oral tissues as compared to the intense staining in the oral squamous cell carcinoma samples at different magnifications.

Normal

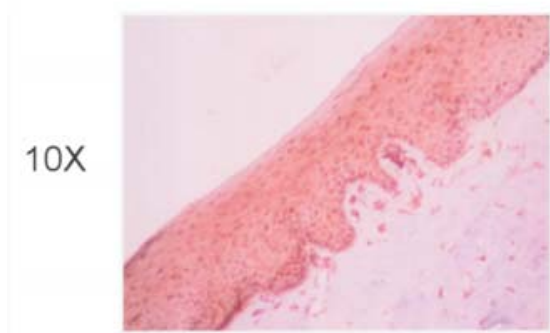

$40 x$

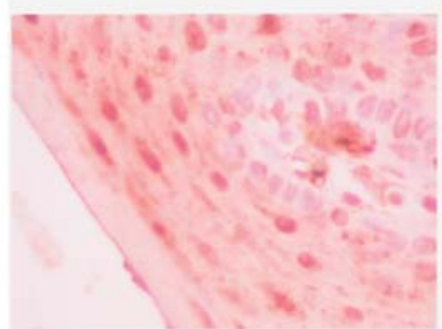

$60 x$

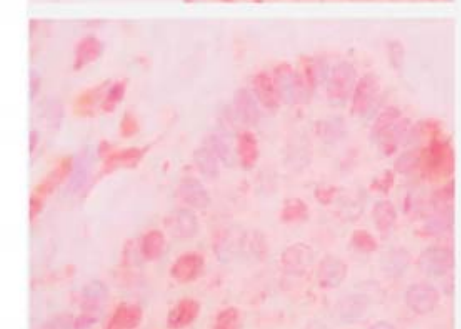

Tumor
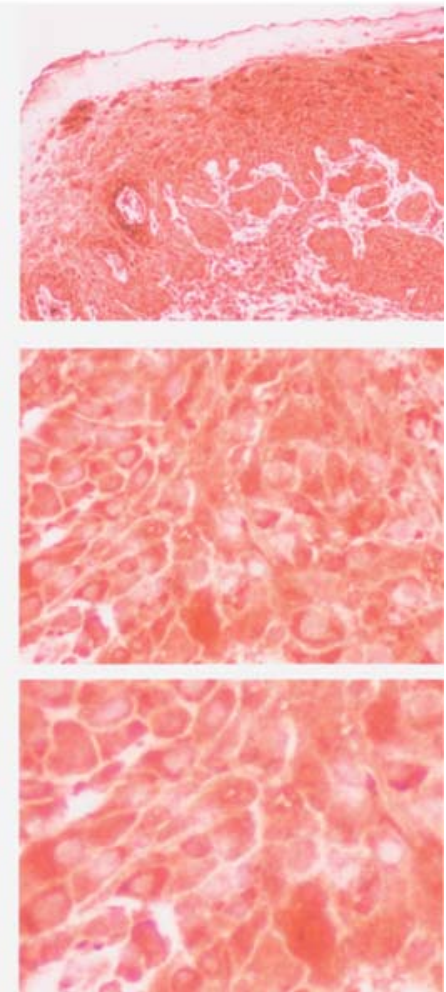

Figure 4. Immunohistochemical analysis of normal and tumor oral samples from patients. The immunohistochemical analysis of normal or tumor oral tissues was carried out as described in 'Materials and methods'. Weak staining of the N-myristoyltransferase inhibitor protein 71/hsc70 was observed in the normal adjacent oral tissues as compared to the intense staining in the oral squamous cell carcinoma samples at different magnifications. 
for NIP71/hsc70 in the oral samples (Fig. 4, normal). The intense staining in the tumor samples (Fig. 4, tumor) is in agreement with earlier reports. The majority of the tumor cells show a nuclear localization of NIP71/hsc70 (Fig. 4, tumor). Heat shock proteins are known to translocate to the nucleus under stress. We have observed that NIP71/hsc70 and NMT interact and, given the chaperon activity of hsc70, it could be possible that due to protein-protein interaction, NMT is localized in the nucleus by hsc70 in tumor cells. The overexpression of NIP71/hsc70 is due to the cells undergoing stress as a result of the tumor load (29). Our results suggest that another aspect of the NIP71/hsc70 overexpression could be to regulate elevated NMT activity in tumor cells. It has recently been shown that the knock down of NMT results in apoptosis $(31,32)$. Our results suggest a novel relationship of NIP71/hsc70 and NMT and assign an important function of NIP71/hsc70 to regulate NMT activity in OSCC. Our results also corroborate the earlier findings that the heat shock protein 70 family is involved in the pathogenesis of oral cancer (30).

\section{Acknowledgements}

This study was supported by grants from the Head and Neck Cancer Foundation of Canada to Drs M.A.C. and R.K.S. and partially supported by the Canadian Institutes of Health Research (CIHR) Grant to Dr R.K.S. Dr A.S. thanks CIHR and the Saskatchewan Health Research Foundation for the postdoctoral fellowship.

\section{References}

1. Boutin JA: Myristoylation. Cell Signal 9: 15-35, 1997.

2. Farazi TA, Waksman G and Gordon JI: The biology and enzymology of protein N-myristoylation. J Biol Chem 276: 39501-39504, 2001.

3. Stehelin D, Varmus HE, Bishop JM and Vogt PK: DNA related to the transforming gene(s) of avian sarcoma viruses is present in normal avian DNA. Nature 260: 170-173, 1976.

4. Krueger JG, Garber EA, Goldberg AR and Hanafusa H: Changes in amino-terminal sequences of pp60src lead to decreased membrane association and decreased in vivo tumorigenicity. Cell 28: 889-896, 1982.

5. Yeatman TJ: A renaissance for SRC. Nat Rev Cancer 4: 470-480, 2004.

6. Dehm SM and Bonham K: SRC gene expression in human cancer: the role of transcriptional activation. Biochem Cell Biol 82: 263-274, 2004.

7. Rajala RV, Datla RS, Moyana TN, Kakkar R, Carlsen SA and Sharma RK: N-myristoyltransferase. Mol Cell Biochem 204: 135-155, 2000.

8. Ebiike H, Masubuchi M, Liu P, et al: Design and synthesis of novel benzofurans as a new class of antifungal agents targeting fungal N-myristoyltransferase. Part 2. Bioorg Med Chem Lett 12: 607-610, 2002.

9. Felsted RL, Glover CJ and Hartman K: Protein N-myristoylation as a chemotherapeutic target for cancer. J Natl Cancer Inst 87: 1571-1573, 1995

10. Shrivastav A, Selvakumar P, Bajaj G, Lu Y, Dimmock JR and Sharma RK: Regulation of N-Myristoyltransferase by novel inhibitor proteins. Cell Biochem Biophys 43: 189-202, 2005.

11. Magnuson BA, Raju RV, Moyana TN and Sharma RK: Increased $\mathrm{N}$-myristoyltransferase activity observed in rat and human colonic tumors. J Natl Cancer Inst 87: 1630-1635, 1995.
12. Raju RV, Moyana TN and Sharma RK: N-Myristoyltransferase overexpression in human colorectal adenocarcinomas. Exp Cell Res 235: 145-154, 1997.

13. Parang K, Wiebe LI, Knaus EE, Huang JS, Tyrrell DL and Csizmadia F: In vitro antiviral activities of myristic acid analogs against human immunodeficiency and hepatitis B viruses. Antiviral Res 34: 75-90, 1997.

14. Rajala RV, Radhi JM, Kakkar R, Datla RS and Sharma RK: Increased expression of $\mathrm{N}$-myristoyltransferase in gallbladder carcinomas. Cancer 88: 1992-1999, 2000.

15. Selvakumar P, Lakshmikuttyamma A, Shrivastav A, Das S, Dimmock JR and Sharma RK: Potential role of N-myristoyltransferase in cancer. Prog Lipid Res 46: 1-36, 2007.

16. Schliephake H: Prognostic relevance of molecular markers of oral cancer (Review). Int J Oral Maxillofac Surg 32: 233-245, 2003.

17. Raju RV, Datla RS and Sharma RK: Overexpression of human $\mathrm{N}$-myristoyltransferase utilizing a T7 polymerase gene expression system. Protein Expr Purif 7: 431-437, 1996.

18. King MJ and Sharma RK: N-myristoyl transferase assay using phosphocellulose paper binding. Anal Biochem 199: 149-153, 1991.

19. Shrivastav A, Pasha MK, Selvakumar P, Singh B and Sharma RK: Expression, localization, and correlation of N-myristoyltransferase and its inhibitor in bovine eye. Invest Ophthalmol Vis Sci 45: 1674-1679, 2004

20. Bradford MM: A rapid and sensitive method for the quantitation of microgram quantities of protein utilizing the principle of protein-dye binding. Anal Biochem 72: 248-254, 1976.

21. Biscardi JS, Tice DA and Parsons SJ: c-Src, receptor tyrosine kinases, and human cancer. Adv Cancer Res 76: 61-119, 1999.

22. Bolen JB, Veillette A, Schwartz AM, DeSeau V and Rosen N: Activation of pp60c-src protein kinase activity in human colon carcinoma. Proc Natl Acad Sci USA 84: 2251-2255, 1987.

23. Buss JE, Solski PA, Schaeffer JP, MacDonald MJ and Der CJ: Activation of the cellular proto-oncogene product p21Ras by addition of a myristylation signal. Science 243: 1600-1603, 1989.

24. Cadwallader KA, Paterson H, Macdonald SG and Hancock JF: $\mathrm{N}$-terminally myristoylated Ras proteins require palmitoylation or a polybasic domain for plasma membrane localization. Mol Cell Biol 14: 4722-4730, 1994.

25. Rajala RV, Kakkar R, Kanthan R, et al: Altered expression and localization of $\mathrm{N}$-myristoyltransferase in experimentally induced rat model of ischemia-reperfusion. J Cell Biochem 86: 509-519, 2002.

26. King MJ and Sharma RK: Identification, purification and characterization of a membrane-associated N-myristoyltransferase inhibitor protein from bovine brain. Biochem J 291: 635-639, 1993.

27. Selvakumar P, Lakshmikuttyamma A, Pasha MK, et al: Nmyristoyltransferase inhibitor protein is homologous to heat shock cognate protein 70. J Cell Biochem 92: 573-578, 2004.

28. Azuma K, Shichijo S, Takedatsu H, Komatsu N, Sawamizu H and Itoh K: Heat shock cognate protein 70 encodes antigenic epitopes recognised by HLA-B4601-restricted cytotoxic T lymphocytes from cancer patients. Br J Cancer 89: 1079-1085, 2003.

29. Maehara Y, Oki E, Abe T, Tokunaga E, Shibahara K, Kakeji Y and Sugimachi K: Overexpression of the heat shock protein HSP70 family and p53 protein and prognosis for patients with gastric cancer. Oncology 58: 144-151, 2000.

30. Kaur J, Srivastava A and Ralhan R: Expression of 70-kDa heat shock protein in oral lesions: marker of biological stress or pathogenicity. Oral Oncol 34: 496-501, 1998.

31. Shrivastav A, Singh NK, Tripathi P, George T, Dimmock JR and Sharma RK: Copper(II) and manganese(III) complexes of N'-[(2-hydroxy phenyl) carbonothioyl] pyridine-2-carbohydrazide: novel therapeutic agents for cancer. Biochimie 88: 1209-1216, 2006.

32. Ducker CE, Upson JJ, French KJ and Smith CD: Two Nmyristoyltransferase isozymes play unique roles in protein myristoylation, proliferation, and apoptosis. Mol Cancer Res 3: 463-476, 2005. 